\title{
Macrophages, T Cell Receptor Usage, and Endothelial Cell Activation in the Pancreas at the Onset of Insulin-dependent Diabetes Mellitus
}

\author{
Arno Hănninen, * Sirpa Jalkanen, "1| Marko Salmi, " "I Sakari Toikkanen, ' George Nikolakaros, * and Olli Simell * \\ Departments of *Pediatrics, ${ }^{\ddagger}$ Medical Microbiology, and ${ }^{\S}$ Pathology, University of Turku, \\ and "National Public Health Institute, SF-20520 Turku, Finland
}

\begin{abstract}
Current knowledge of the phenotype of mononuclear cells accumulating in pancreatic islets in insulin-dependent diabetes (IDDM) and factors determining their homing into the pancreas is limited. Therefore, a pancreas obtained at the onset of IDDM was studied in detail. Cryostat sections were stained for mononuclear cell types, $T$ cell receptor subtypes, and adhesion molecules of vascular endothelium and studied by immunofluorescence microscopy, and peripheral blood mononuclear cells were phenotyped using flow cytometry. Monocytes/macrophages (lysozyme- or CD 14-reactive cells) were identified among other mononuclear cell types in islet infiltrates. $\mathrm{V} \beta$ 8-positive $T$ cells were overrepresented, but $T$ cells with other $V \beta$ s studied ( $V \beta$ 5, V $\beta$ 5.1, V $\beta$ 6, V $\beta$ 12) were also found. The vascular endothelium of the islets and many small vessels nearby islets strongly expressed intercellular adhesion molecule-1, whereas vascular cell adhesion molecule-1 and E-selectin were totally absent. We conclude: $(a)$ that increased expression of intercellular adhesion molecule-1 on vascular endothelium may increase endothelial adhesion of mononuclear cells and enhance their accumulation in the pancreas during diabetic insulitis; ( $b$ ) that $T$ cells with certain $T$ cell receptors can be enriched in infiltrated pancreatic islets; and (c) that macrophages and antigen-specific CD 8-positive $T$ cells are involved in pancreatic beta cell destruction at the onset of IDDM. $(J$. Clin. Invest. 1992. 90:1901-1910.) Key words: islets of Langerhans $\bullet$ insulitis $\bullet$ inflammation $\bullet$ adhesion molecules $\bullet T$ cells
\end{abstract}

\section{Introduction}

Before the advent of the clinical symptoms of insulin-dependent diabetes mellitus (IDDM), ${ }^{1}$ mononuclear cells infiltrate in the human pancreas, mainly islets of Langerhans, and lead to destruction of insulin producing beta cells (1). Current knowledge of immunologic phenomena in the pancreas during this process is limited, and only one diabetic pancreas has previ-

Address correspondence to Dr. Arno Hänninen, Department of Pediatrics, University of Turku, Kiinamyllynkatu 4-8, SF 20520, Turku, Finland.

Received for publication 31 January 1992 and in revised form 29 April 1992.

1. Abbreviations used in this paper: ICAM-1, intercellular adhesion molecule-1; IDDM, insulin-dependent diabetes mellitus; E-selectin, endothelial leukocyte adhesion molecule-1; VCAM-1, vascular cell adhesion molecule-1.

J. Clin. Invest.

(c) The American Society for Clinical Investigation, Inc. $0021-9738 / 92 / 11 / 1901 / 10 \quad \$ 2.00$

Volume 90, November 1992, 1901-1910 ously been analyzed for mononuclear cell subsets (2). In that pancreas, the majority of infiltrating cells were CD 8 positive (cytotoxic/suppressor) T lymphocytes. To a lesser extent, pancreatic islets also contained helper T lymphocytes, B lymphocytes, and natural killer cells. In support of the hypothesis that beta cells could themselves present their surface antigens to the immune system, some beta cells with HLA class II expression were found.

Conventionally, it is the macrophage, which strongly expresses HLA class II molecules, and is active in antigen presentation. The occurrence of macrophages in islets of human pancreas during diabetic insulitis, however, remained unconfirmed in the previous study (2). By plain morphology, cells resembling macrophages have been identified in islet infiltrates in IDDM (1). By more specific detection methods macrophages have been identified in pancreatic grafts affected by mononuclear cell infiltration (3).

Extravasation of mononuclear cells from the blood stream is initiated by their adhesion to vascular endothelium (4). This interaction is controlled by regulated surface expression of adhesion receptors on inflammatory cells, e.g., leukocytes, and their ligands on vascular endothelial cells (5). ICAM-1 (intercellular adhesion molecule-1), VCAM-1 (vascular cell adhesion molecule-1) and E-selectin (endothelial leukocyte adhesion molecule-1) are endothelial adhesion molecules induced by inflammatory mediators (6-10). At the site of inflammation their expression correlates well with the accumulation of mononuclear cells (11-14). At least these adhesion molecules on the endothelial cells of target organs may, therefore, be involved in the regulation of the inflammatory response.

The potential role of $\mathrm{T}$ cell receptor structure in autoimmune diseases has become evident in animal experiments (1519) which have shown that the immune response against self can be oligoclonal. In nonobese diabetic mice, islet-infiltrating $T$ cells seem to be heterogenous with respect to $V \beta$ usage (20). In human diabetes, however, quantitation of $\mathrm{T}$ cell receptor $\mathrm{V} \beta$ usage in activated $\mathrm{T}$ cells in the peripheral blood has suggested that $\mathrm{T}$ cell response is oligoclonal, but different receptor elements are used in different individuals (21).

This study was undertaken to clarify some aspects of antigen presentation, $T$ cell receptor usage, and the function of vascular endothelium in the diabetic pancreas to recognize potential targets of interventional treatment in the cascade leading to beta cell destruction. To this end, we studied expression of HLA antigens and adhesion molecule ICAM-1 on beta cells, $T$ cell receptor phenotypes of infiltrating $T$ lymphocytes, and the expression of vascular adhesion molecules in the pancreas at the onset of IDDM.

\section{Methods}

Case report. An 8-yr-old girl without recent viral or other infections or family history of diabetes or other endocrine or autoimmune diseases 
was hospitalized after a two-week history of polyuria, vomiting, and loss of weight. She developed brain edema within hours of admission to hospital and lost spontaneous respiration as well as cortical functions of the brain. Intensive care was discontinued two days later after confirmation of brain death. The pancreas for this study was obtained at autopsy after informed consent of the parents. The HLA type of the child was HLA A 2,3; B 18,40; w 6; Cw -; DR 4. IgG-antibody titers for enteroviruses and common respiratory viruses (adeno, influenza $A$ and $B$, and parainfluenza I-III) were normal. Virus inoculation from the pancreas was negative. In histopathologic examination of tissues, lymphocytic thyroiditis was diagnosed.

Staining of paraffin-fixed pancreatic sections. Pieces from the tail of the pancreas were cut into 5- $\mu \mathrm{m}$ sections and stained using immunoperoxidase method (Vectastain Elite Kit; Vector Laboratories, Burlingame, CA) with anti-LCA (leukocyte common antigen, CD 45; Dakopatts, Glostrup, Denmark), anti-CD 3 (Dakopatts), and anti-B-cell (L-26, Dakopatts) antibodies for detection of infiltrating leukocytes, and $T$ and $B$ lymphocytes, respectively. Antilysozyme antibody (Dakopatts) was used to demonstrate lysosome-containing phagocytic cells (macrophages and neutrophils) among infiltrating cells. The Leder staining was used to demonstrate neutrophilic leukocytes solely.

Immunofluorescence staining. For immunofluorescence studies, two pieces from the tail of the pancreas were snap frozen in liquid nitrogen and stored at $-70^{\circ} \mathrm{C}$. The time lag between the death and freezing of tissue samples was $5 \mathrm{~h}$. Normal pancreases from two organ donors (one adult, one 15-yr-old child) were cut, frozen, and stored with an equal or shorter time lag. Serial $5-\mu \mathrm{m}$ sections were cut and fixed in cold acetone ( $5 \mathrm{~min}$ ). The phenotype of mononuclear cells was analyzed by staining the sections with monoclonal antibodies against: CD 4 (Immunotech, Marseille, France); CD 8 (CRL 8014; American Type Culture Collection, Rockville, MD); CD 14 (My 4), CD 20 (B 1), and HLA DR (I 2) (Coulter Immunology, Hialeah, FL); HLA ABC (Sera-lab, Crawley Down, Sussex, UK); and V $\beta$ 5-, V $\beta$ 6-, V $\beta$ 8-, $\mathrm{V} \beta \quad 12-$, and $\gamma / \delta-T$ cell receptors (Diversi-T ${ }^{\mathrm{TM}}$ and Identi-T TCR $\gamma 1^{\text {TM }}$; T Cell Sciences, Cambridge, MA). Monoclonal antibodies against endothelial cell adhesion molecules (ICAM-1, VCAM-1, E-selectin) were generous gifts from Dr. D. Haskard, Hammersmith Hospital, London (22). Monoclonal antibody 3G6 against chicken T cells was used as a negative control. Insulin was detected by a polyclonal guinea pig antibody against insulin (Accurate Chemicals, Westbury, NY). Fluorescein-conjugated sheep anti-mouse IgG (FITC-antimouse; Sigma Chemical Co., St. Louis, MO) and rhodamine-conjugated goat anti-guinea pig IgG (TRITC-anti-guinea pig; Accurate Chemicals) were used as second-stage antibodies against monoclonal antibodies or antiinsulin antibody, respectively. At each stage, tissue sections were incubated with antibodies at room temperature ( $30 \mathrm{~min})$ and then washed three times ( 5 min each) in PBS. When anti-T cell receptor antibodies were used, the first and second steps were repeated to enhance staining intensity. In each experiment, parallel sections were stained using monoclonal antibody $3 \mathrm{G} 6$ as a negative control. Optimal concentrations of all monoclonal antibodies used were pretested in other tissues. Each staining was repeated at least twice, HLA class II staining was done five times. In two-color immunofluorescence staining, sections were stained in four separate steps, by monoclonal antibodies, second stage FITC-conjugated antibody, polyclonal antiinsulin, and TRITC-anti-guinea pig IgG antibody, with washings between each step. TRITC-anti-guinea pig IgG was diluted in PBS containing 5\% normal mouse serum to absorb any anti-mouse antibodies that could cross-react with monoclonal mouse IgG used for detection of cell surface molecules. Sections were mounted in glycerol-PBS $(90 \%$ glycerol) containing phenylendiamine to diminish fluorescence decay and viewed under a Leitz microscope with ultraviolet light source. Photographs were taken on Kodachrome 800/1,600 ASA film.

Analysis of peripheral blood mononuclear cells. Peripheral blood mononuclear cells were isolated using Ficoll gradient centrifugation (Pharmacia, Uppsala, Sweden), washed in RPMI 1640, and suspended in $90 \%$ human serum (Finnish Red Cross, Helsinki, Finland) and $10 \%$ dimethylsulfoxide (Merc, Darmstadt, Germany) to be stored at $-70^{\circ} \mathrm{C}$. After thawing and washing, the cells were stained for immunofluorescence. Staining was essentially done as previously described (23). Briefly, 500,000 cells were incubated with first-stage antibodies (T Cell Sciences) for $15 \mathrm{~min}$ on ice. After two washings in PBS containing 5\% FCS and $1 \mathrm{mM}$ sodium azide, second-stage FITC-conjugated sheep anti-mouse IgG (Sigma Chemical Co.) was added for another 15 min. After washings, cells were fixed in PBS containing $1 \%$ formaldehyde and subsequently analyzed using a FACScan ${ }^{\circledR}$ cytometer (Becton Dickinson, Mountain View, CA)

\section{Results}

Mononuclear cells in the pancreas. The intensity of mononuclear cell infiltration in different sections of the pancreas varied. Degree of insulitis and number of leukocytes, $T$ cells, B cells, and phagocytes in islet infiltrates were evaluated in an area, where the majority of islets $(85 \%)$ were affected by insulitis (Table I). T cells were found to be more numerous in islets with mild and moderate insulitis whereas in islets with severe insulitis, numbers of $T$ cells and B cells were almost equal. A few lysosome-containing phagocytic cells (macrophages or neutrophils) were present in $80 \%$ of infiltrated islets (Fig. 1), whereas the Leder method could detect only one cell in 42 islets analyzed with this method, indicating almost total absence of neutrophils. Some lysosome-containing cells were also present in a control pancreas but never close to islets.

In immunofluorescence staining, the majority of infiltrating cells were CD 8 positive (cytotoxic/suppressor) lymphocytes occurring around and inside the islets (mean 33 positive cells/islet section in 49 islets) and also amply present as single cells in the exocrine areas of the pancreas. CD 14-positive cells (macrophages) were also frequent in the exocrine pancreas. Some CD 14-positive cells had accumulated in the peripheral parts of the islets and a few inside them (Fig. 2). Occasional CD 14-positive cells were identified also in the two control pancreases but more sporadically (possibly resident macrophages) and not in contact with endocrine islets. CD 4-positive (helper/inducer) lymphocytes were present in and around most islets affected by insulitis and often localized on the islet periphery (mean 19 positive cells/islet section in 45 islets). CD 20-positive cells ( $B$ lymphocytes) were absent from the cores of the islets but present in clusters on the islet periphery.

Expression of HLA molecules. HLA class I molecules were strongly expressed on all endocrine cells of the islets. In control

Table I. Degree of Insulitis and Numbers of Infiltrating Cells in 35-43 Islets Examined for the Presence of Leukocytes, Phagocytes, and $T$ and $B$ Lymphocytes in Sections of a Pancreas at the Onset of IDDM

\begin{tabular}{|c|c|c|c|c|c|}
\hline $\begin{array}{l}\text { Degree of } \\
\text { insulitis }\end{array}$ & $\begin{array}{l}\text { Percentage } \\
\text { of islets }\end{array}$ & Leukocytes* & $\mathrm{T}$ cells ${ }^{\ddagger}$ & B cells & Phagocytes" \\
\hline Mild & 40 & $\begin{array}{c}1-9 \\
\text { Mean } 5.4\end{array}$ & $\begin{array}{c}1-7 \\
\text { Mean 3.4 }\end{array}$ & $\begin{array}{c}0-3 \\
\text { Mean } 1.7\end{array}$ & $\begin{array}{c}0-2 \\
\text { Mean 0.8 }\end{array}$ \\
\hline Moderate & 18 & $\begin{array}{c}14-29 \\
\text { Mean } 22.0\end{array}$ & $\begin{array}{c}8-26 \\
\text { Mean 12.1 }\end{array}$ & $\begin{array}{c}5-11 \\
\text { Mean } 7.5\end{array}$ & $\begin{array}{c}0-4 \\
\text { Mean 2.0 }\end{array}$ \\
\hline Severe & 27 & $\begin{array}{c}34-182 \\
\text { Mean } 77.8\end{array}$ & $\begin{array}{c}20-70 \\
\text { Mean 37.1 }\end{array}$ & $\begin{array}{c}12-84 \\
\text { Mean 33.8 }\end{array}$ & $\begin{array}{c}3-9 \\
\text { Mean 5.5 }\end{array}$ \\
\hline
\end{tabular}

Islets were graded according to the degree of insulitis: mild, 1-9; moderate, 10 29 ; severe $\geq 30$ infiltrating cells inside the islet.

Infiltrating cell types were analyzed in immunoperoxidase staining using antibodies as indicated: * anti-leukocyte common antigen (CD 45); ${ }^{\star}$ anti-CD 3; L-26; " antilysozyme. 

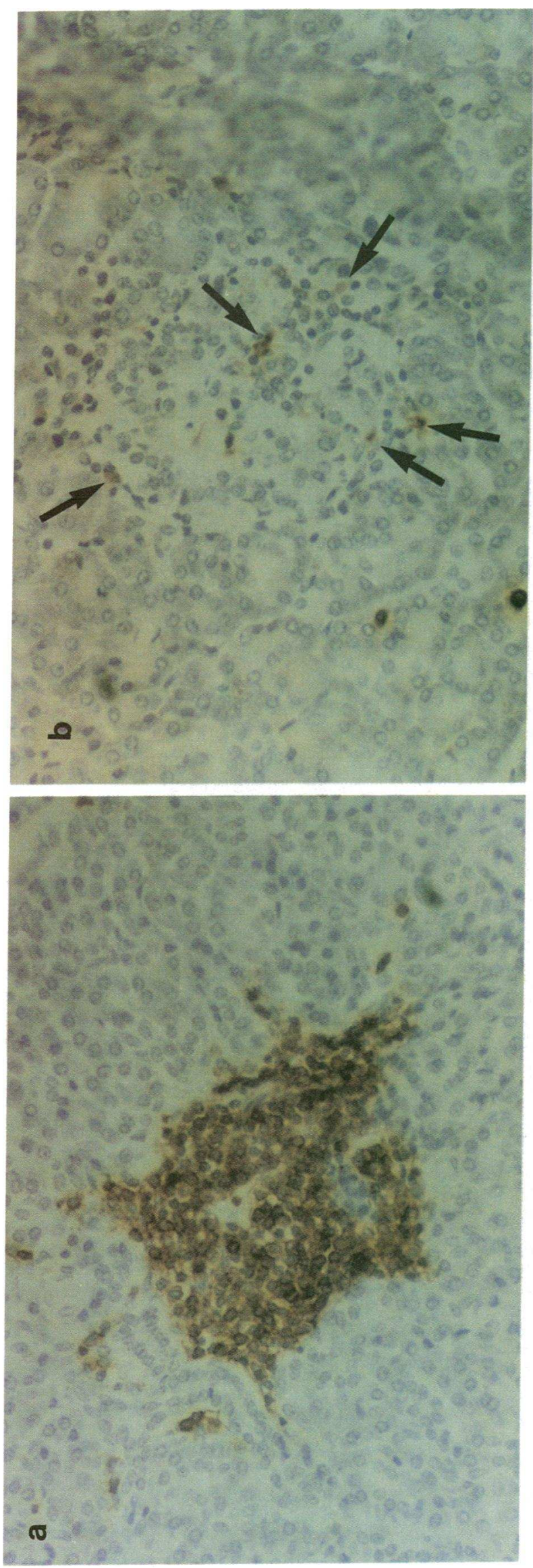

pancreases, endocrine cells were weakly stained. In the diabetic pancreas, HLA class II molecules were overexpressed on vascular endothelium lining capillaries and capillary sinusoids in the islets (Fig. 3). Clusters of infiltrating cells were also overexpressing class II molecules, suggesting that these cells had previously been activated. HLA class II molecules were strongly stained also on the endothelium of some larger vessels in the exocrine pancreas near islets affected by insulitis. Although some HLA class II staining was also detectable in control pancreases, it was weaker and more diffuse (Fig. 4). In two-color immunofluorescence studies the insulin positive beta cells of the islets did not stain for HLA class II molecules but were surrounded by infiltrating, HLA class II-positive cells. Neither was ICAM-1 expression localized on insulin positive cells (data not shown ). In ICAM-1 staining, infiltrating cells and cell clusters remained largely unstained.

Adhesion molecules on vascular endothelium. Expression of three adhesion molecules, ICAM-1, VCAM-1, and E-selectin, on vascular endothelium in the pancreas was studied in an attempt to characterize mechanisms controlling leukocyte adherence and emigration from the blood into the pancreas in IDDM. It was found that capillary endothelial cells in islets were usually strongly positive for ICAM-1, and the pattern of staining was similar to that for HLA class II. Many blood vessels stained strongly for ICAM-1 also in the exocrine pancreas. ICAM-1 was also expressed on the vessels of control pancreases but with lower intensity (Fig. 4). In the diabetic pancreas, VCAM-1 was expressed on scattered cells surrounding the islet, morphologically resembling dendritic cells. VCAM-1 was not expressed on endothelium in islets or in exocrine areas of the diabetic pancreas or control pancreases. Interestingly, E-selectin stained no venules in the diabetic pancreas. Neither was E-selectin expressed in control pancreases (not shown).

$T$ cell receptor usage analysis. The usage of $\mathrm{T}$ cell receptors was evaluated by studying the expression of five different beta chain variable regions (Table II) and gamma/delta receptors. $\mathrm{V} \beta$ 8-bearing $\mathrm{T}$ lymphocytes were numerous on the islet periphery as well as in islet cores (usually 8-14 positive cells per islet section). Some cells bore $V \beta 5$ and $V \beta 5.1$ receptors (three to five per islet section) mainly on the islet periphery. $V \beta 6$ and $\mathrm{V} \beta 12$ were present in almost all islets examined but the maximum number of positive cells per islet section was one or two. T cells with $\gamma / \delta$ T cell receptors were not found. The occurrence of all five $V \beta s$ studied on different $T$ cells infiltrating islets indicates the presence of a diverse population of $T$ cells in the islets.

The expression of different $V \beta s$ in the peripheral blood was evaluated using immunofluorescence staining and flow cytometry to be compared to that of islet-infiltrating $T$ cells. The distribution of $T$ cells with different $V \beta s$ was normal, as none of the cell populations was overrepresented (net percentage of cells bearing $\mathrm{V} \beta 5,5.1,6,8$, and $12 \mathrm{~T}$ cell receptors was approximately $2,2,3,3$ and $1 \%$, respectively) (Fig. 5). The percentage of $T$ cells bearing different $V \beta s$ in the peripheral blood was used for an estimate of the expected number of $T$ cells bearing these

Figure 1. Infiltration of islets by inflammatory and phagocytic cells (macrophages). (a) Leukocyte common antigen staining of a severely infiltrated islet; $(b)$ lysozyme staining of another islet (arrows indicate positively stained cells $)(\times 100$, immunoperoxidase method, Meyer's hematoxylin counterstain ). 

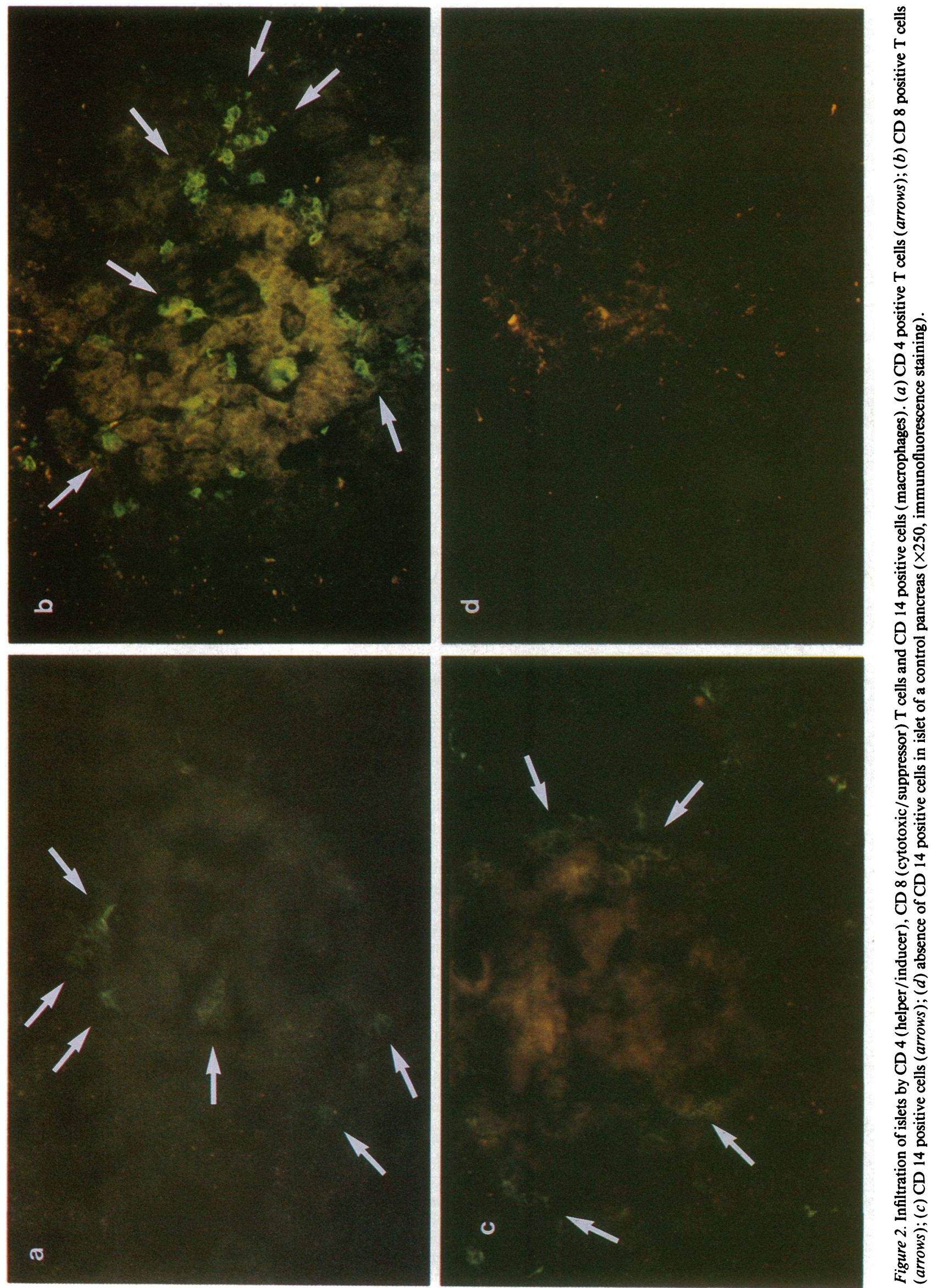

(⿻)

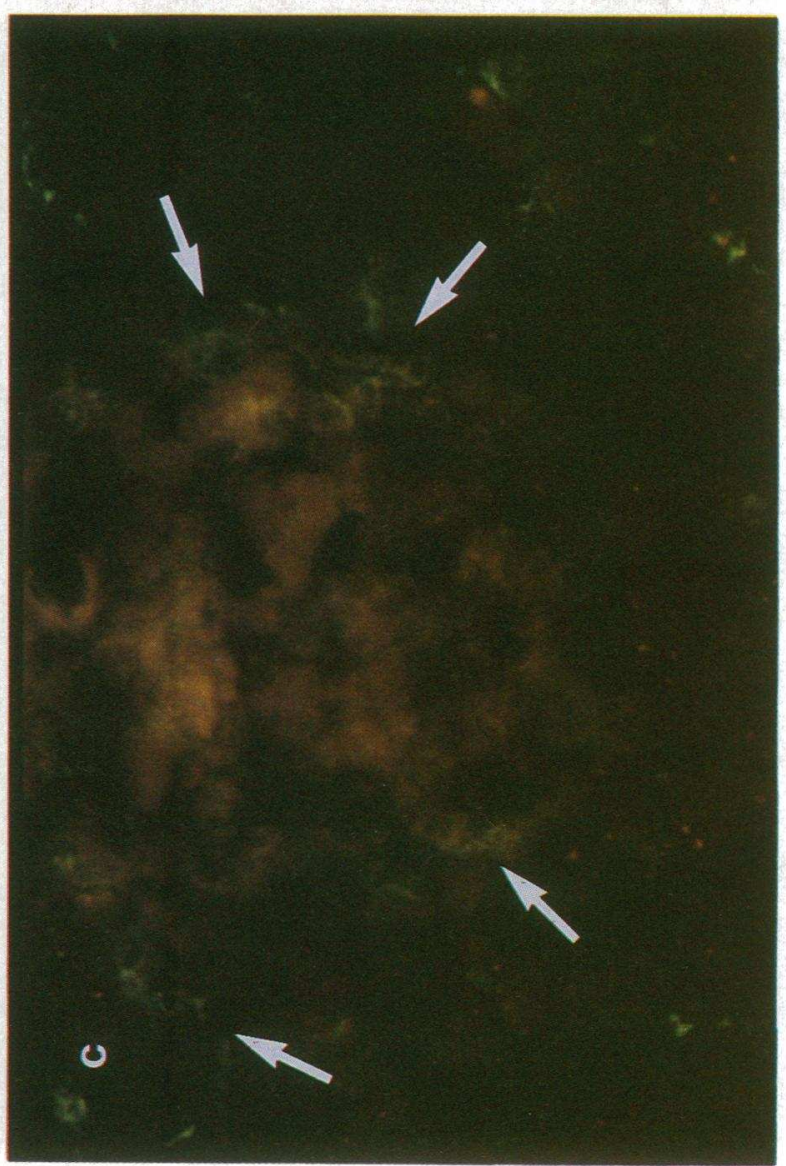

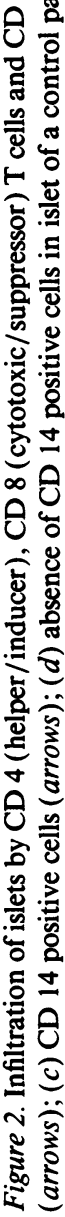



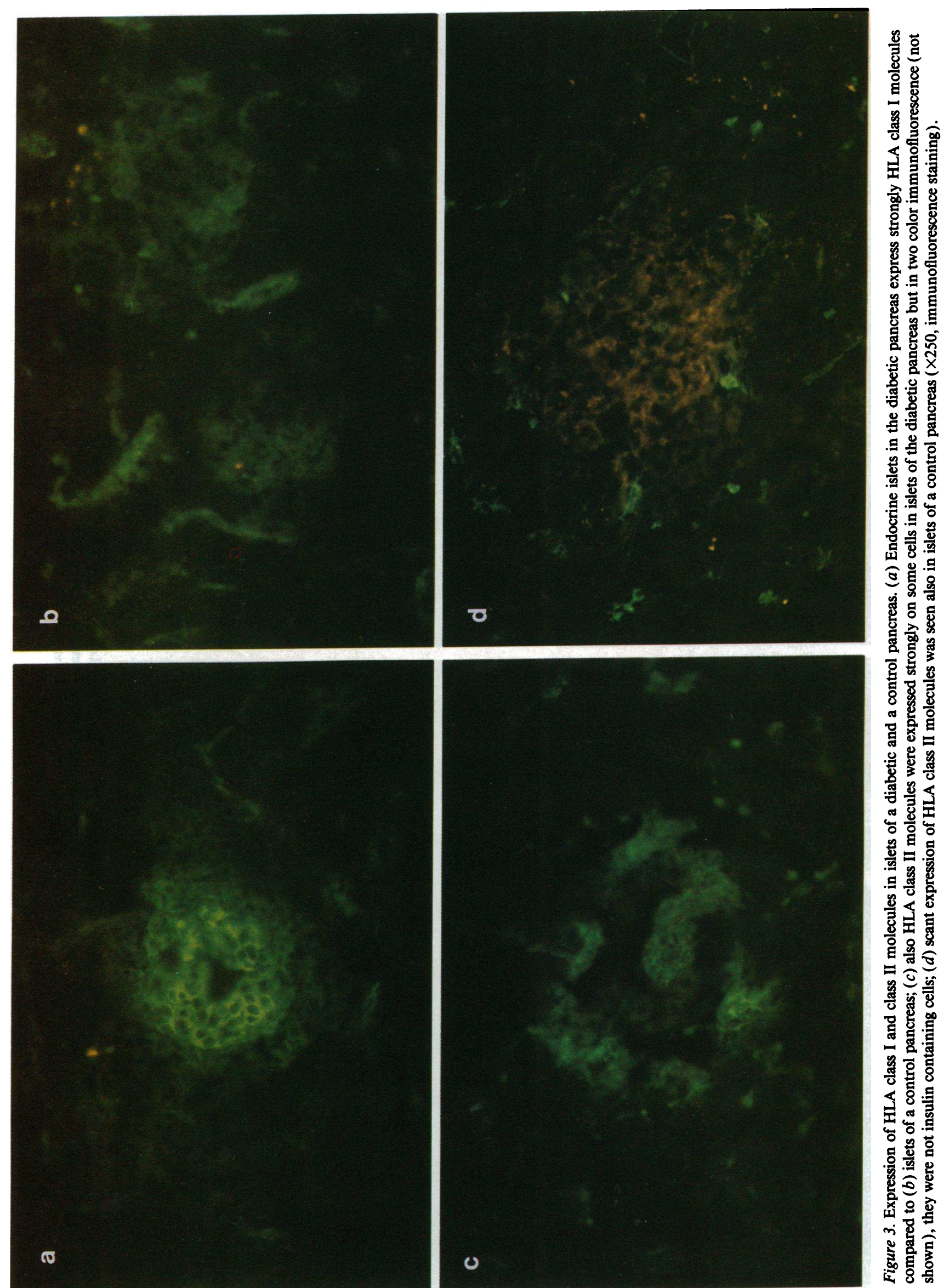


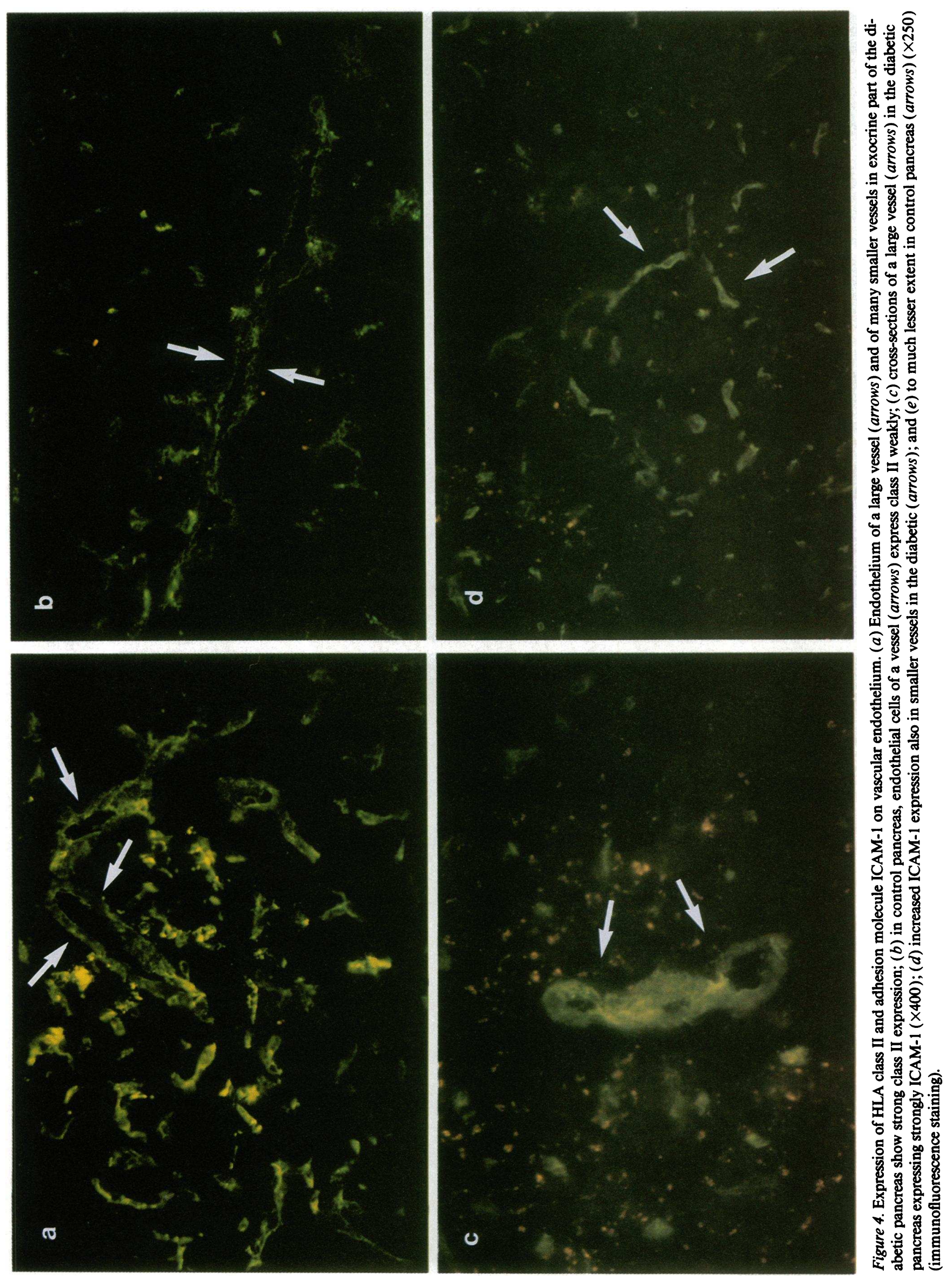



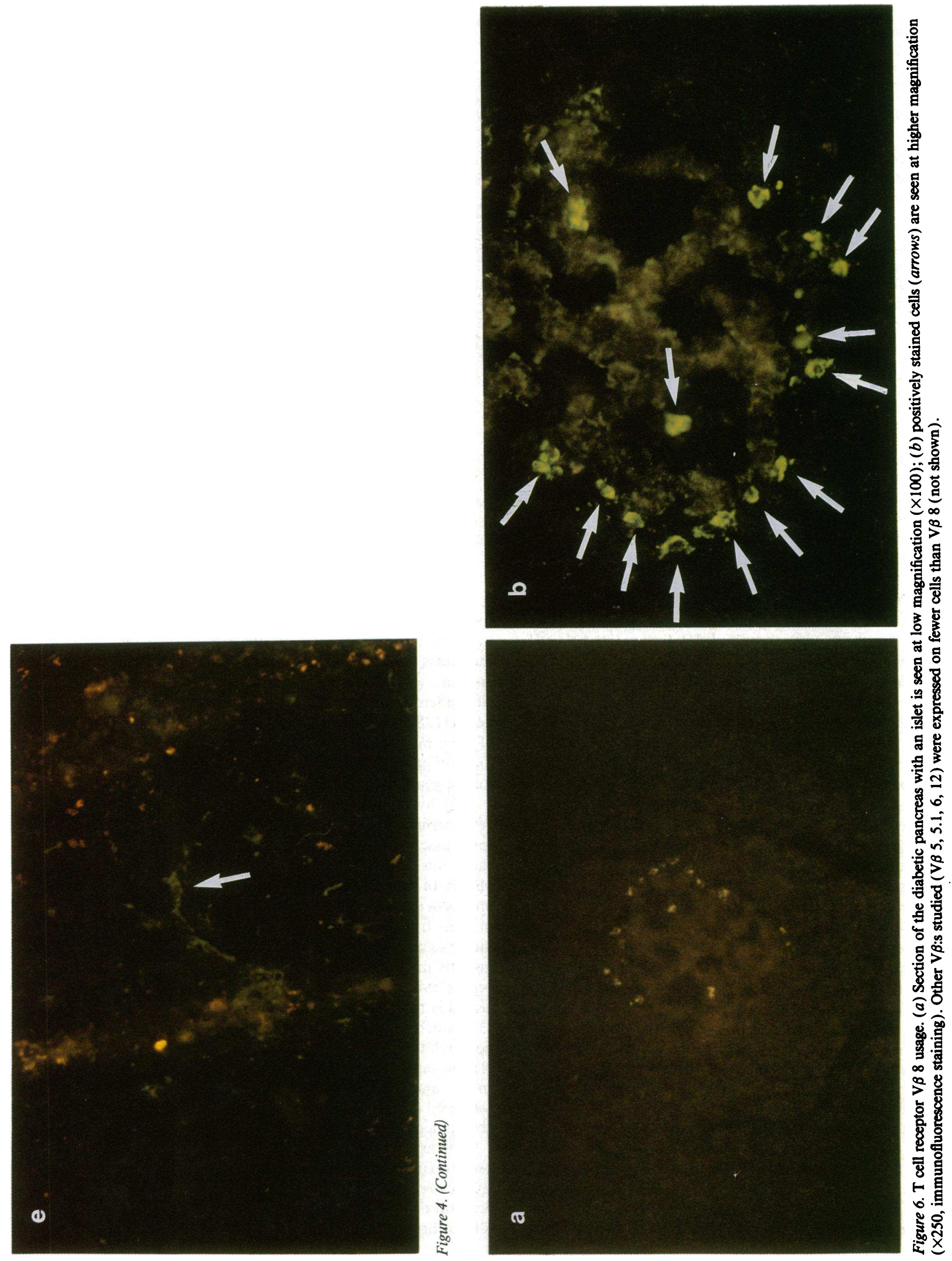
Table II. T Cell Receptor Usage in T Cells which have Infiltrated Islets of Langerhans in the Pancreas at the Onset of IDDM

\begin{tabular}{ccc}
\hline $\begin{array}{c}\text { T cell receptor } \\
\text { phenotype }\end{array}$ & $\begin{array}{c}\text { Cells per islet } \\
\text { section }\end{array}$ & Expected $^{*}$ \\
\hline V $\beta 5$ & $3-5$ & $(2)$ \\
V $\beta 5.1$ & $3-5$ & $(2)$ \\
V $\beta 6$ & $1-2$ & $(3)$ \\
V $\beta 8$ & $8-14$ & $(3)$ \\
V $\beta$ 12 & $1-2$ & $(1)$ \\
\hline
\end{tabular}

* Positively stained cells per one section of an islet. For each $\mathrm{V} \beta$ phenotype, 17-25 islets were analyzed. ${ }^{\ddagger}$ Expected number of positive cells was calculated according to the percentage of cells detected in peripheral blood by flow cytometry, $1 \%$ corresponds one cell (total number of lymphocytes per section of a large islet was $\sim 100$ ).

$\mathrm{V} \beta \mathrm{s}$ in the pancreas per islet section (Table II). Actual counting of cells in islet sections showed that $\mathrm{V} \beta$ 8-bearing $\mathrm{T}$ cells were enriched in islet infiltrates (Fig. 6).

\section{Discussion}

Although our study is based on a single case of IDDM because of the extremely limited availability of pancreatic tissue immediately after onset of the disease, we firmly believe that our findings clarify the pathogenesis of common type 1 diabetes (24). First, our observations confirm that mononuclear cells infiltrating pancreatic islets during florid insulitis are overwhelmingly CD 8-positive (cytotoxic/suppressor) T lymphocytes and that the expression of both HLA class I and class II molecules in the islets is increased, as was in the other human pancreas at the onset of IDDM previously reported (2). Second, even though not overrepresented compared to other mononuclear cell types, lysozyme-positive cells and CD 14-positive cells, i.e., macrophages, were present in many pancreatic islets during insulitis. The possibility that neutrophils, which are lysozyme positive and 5-50\% of which have CD 14 on their cell surface, were responsible for lysozyme or CD 14 staining was excluded by light microscopy which showed practically no polymorphonuclear cells in islet infiltrates or in exocrine pancreas and by Leder staining, which showed only one neutrophil in 42 islets analyzed with this method. In accordance with our finding, quite recently, macrophages have been demonstrated also in routinely fixed pancreases in IDDM (25). Third, in islets we recognized subsets of $T$ cells with various types of $T$ cell receptors. Imbalance was detected in the five $T$ cell receptor phenotypes studied, as $\mathrm{V} \beta 8 \mathrm{~T}$ cells were most abundant, $\mathrm{V} \beta 5$ and $\mathrm{V} \beta 5.1 \mathrm{~T}$ cells numerous, and $\mathrm{V} \beta 6$ and $\mathrm{V} \beta 12 \mathrm{~T}$ cells were few. $\gamma / \delta$ T cells were absent. Fourth, we confirmed that vascular endothelium is activated during insulitis and showed that many vessels overexpress HLA class II molecules and the adhesion molecule ICAM-1 but no VCAM-1 or E-selectin.

According to previous studies $(2,26,27)$, some beta cells in the diabetic pancreas express HLA class II antigens typically expressed on certain lymphoid cells as well as on macrophages and other antigen presenting cells. However, we were not able to detect HLA class II expression on beta cells in this pancreas. One explanation for this discrepancy is that almost all islets now analyzed were affected by insulitis and infiltrated by mononuclear cells, and in previous studies $(26,27)$, class II express-

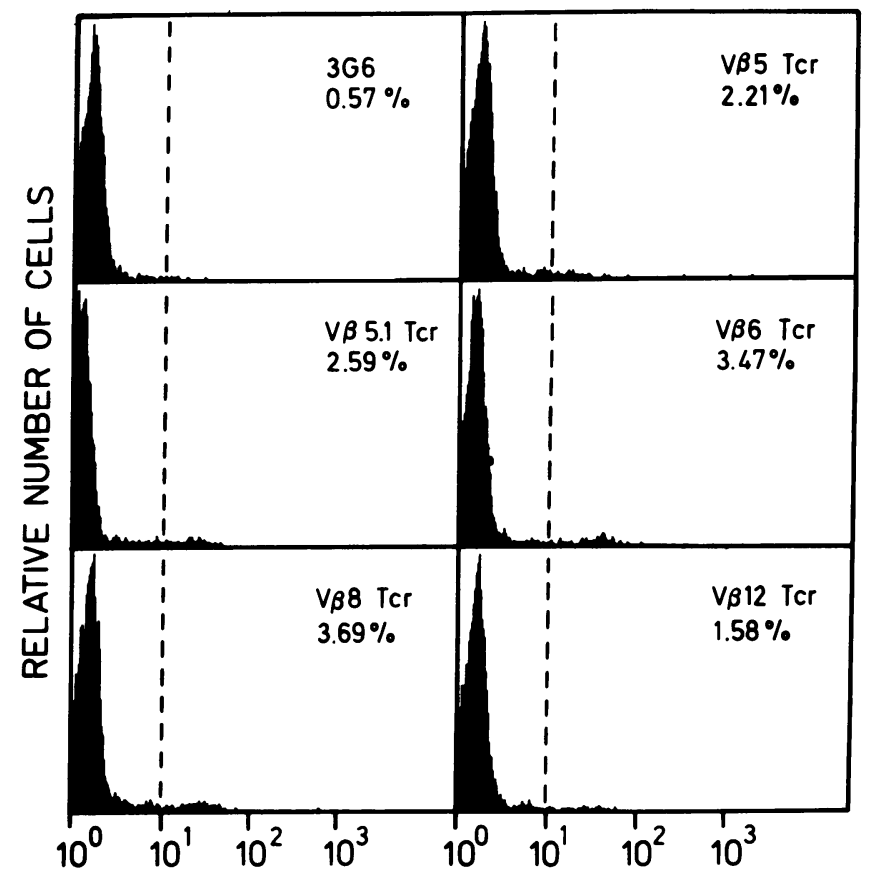

Figure 5. A flow cytometry analysis of $\mathrm{T}$ cell receptor usage in peripheral blood mononuclear cells of the patient. Percentage of cells which stained positively with the monoclonal antibody indicated is shown in each panel.

ing beta cells were more often recognized in islets devoid of inflammatory cells. Hypothetically, expression of HLA class II molecules on beta cells could lead to presentation of beta cellantigens to $T$ lymphocytes, but probably some adhesion strengthening molecules, including ICAM-1, would also be needed (28). Since we were not able to find expression of either of these molecules on beta cells, we find it likely, that in this diabetic pancreas, beta cells themselves were not responsible for antigen presentation.

The hypothesis that interleukin-1 may have a role in beta cell destruction (29) is given some support by the finding that some macrophages were present in islets during insulitis, because interleukin- 1 is secreted mainly by activated macrophages. In concordance with speculations of the role of macrophages in the pathogenesis of IDDM, macrophages are present in islets from an early phase of cell infiltration and various therapies directed against macrophages prevent progression of insulitis in animal models of spontaneous autoimmune diabetes (30-32). In experimental conditions, macrophages are also able to engulf insulin granules from damaged beta cells (33) which could happen also in vivo during beta cell destruction and, to some extent, could account for class II expression of some insulin-containing cells found in the diabetic pancreas. In the pancreas of the present study, some CD 14-positive cells were seen next to insulin containing beta cells, but we were not able to detect $C D 14$ staining on insulin containing cells.

The extravasation of leukocytes to an inflamed organ depends on interaction between adhesion molecules expressed on leukocytes and endothelium. It is believed that increased expression of VCAM-1 on endothelial cells plays an important role in chronic inflammatory diseases (34). In the diabetic human pancreas of the present study, VCAM-1 expression was 
exclusively observed on single cells on the islet periphery. Morphologically, these cells appeared not to be endothelial. In addition to endothelial cells, VCAM-1 is, in fact, expressed on dendritic cells and macrophages in uninflamed lymph nodes, Peyer's patches, and spleen (35), suggesting that the cells observed on the islet periphery were macrophages or dendritic cells. Our finding that E-selectin was absent in this diabetic pancreas where the number of polymorphonuclear leukocytes was low agrees with the concept that ELAM-1 preferentially mediates neutrophil extravasation $(9,10)$. Because binding of mononuclear cells to ICAM-1 of endothelial cells is an important step in extravasation, and because hyperexpression of this molecule was observed, we conclude that endothelial cells are likely to mediate inflammatory cell adhesion and extravasation into the pancreas during diabetic insulitis, at least in part, by regulating expression of this adhesion molecule. Studies in experimental allergic encephalomyelitis (36) suggest that interaction between lymphocytes inducing the disease and endothelial cells in the target tissue is an important step in the development of this disease. Our finding of strong HLA class II and ICAM-1 expression on endothelium indicates that endothelial cells in the pancreas may well be of similar importance in the development of IDDM. Further, our results imply that expression of VCAM-1 and E-selectin on vascular endothelium is not needed for mononuclear cell infiltration into pancreatic islets.

The increased expression of HLA-DR and ICAM-1 on the endothelium of some medium size vessels in the exocrine pancreas may indicate that the site of extravasation of inflammatory cells is not limited to the capillary network of endocrine islets. Actually we observed infiltration of inflammatory cells also into the interstitium of the exocrine part of the diabetic pancreas. Since antigens in pancreatic beta cells probably do not participate in tolerance induction during $T$ cell development in the thymus $(37,38)$, it could be hypothesized that an inflammatory process even in the exocrine pancreas causing increased endothelial adhesion and extravasation of inflammatory cells may lead to a situation where lymphocytes with potential anti-beta cell reactivity have access to the organ.

The enrichment of $T$ cells with $\mathrm{V} \beta 8 \mathrm{~T}$ cell receptor phenotype in islet infiltrates may suggest that $V \beta 8$ is an important $T$ cell receptor structure in autoimmunity against insulin-producing beta cells. However, in nonobese diabetic mice, an animal model of type 1 diabetes, beta cell reactive $T$ cell clones seem to use a diverse selection of $T$ cell receptors (39). In addition, deletion from $T$ cell repertoire of $T$ cells with certain $T$ cell receptor elements, which have previously been suggested to be used by autoreactive $T$ cells in these mice, does not give protection against autoimmune diabetes (40). One explanation of these findings is that the beta cell reactive $T$ cell clones recognize different antigenic determinants, all of which are not necessarily primary targets on beta cells, and that the required $T$ cell receptor phenotype for initiating beta cell reactivity was not among the deleted $T$ cell receptor phenotypes (40). Thus, it is still possible, provided that these explanations are correct, that the $\mathrm{T}$ cell response against beta cells also in spontaneous murine diabetes commences as an oligoclonal response of $\mathrm{V} \beta$ 16-bearing $T$ cells as an example (39). In light of these observations, $V \beta 8$ can not be directly interpreted as a candidate for a $T$ cell receptor structure required to initiate autoaggression against beta cells in IDDM. However, the enrichment of $\mathrm{V} \beta$ 8-bearing $T$ cells suggests that they are a subpopulation of $T$ cells that recognize some antigen in islets, and that $T$ cells are important in the disease process, also during the onset of the disease. The excess of CD 8-positive $T$ cells in infiltrated islets and increased expression of molecules recognized by these cells, i.e., HLA class I molecules, on islet cells further suggests that one important mechanism by which beta cells are destroyed, is direct action of cytotoxic $T$ cells. Given their function in destroying target cells infected by viral pathogens (41) and given the detected increase in expression of HLA class I molecules on beta cells after virus infection (42), it is interesting to speculate on possible involvement of a virus also in triggering the autoimmune process leading to beta cell destruction, although in this case of IDDM no evidence of an association between a virus and the disease process was obtained.

Based on our observations, we propose the following hypothesis on events in pancreatic islets which would lead to autoimmune beta cell destruction: Due to some as-yet nondefined environmental insult (43) in the islet (viral infection?), cytokines and other inflammatory mediators are released that elicit activation of vascular endothelium $(44,45)$. Endothelial activation in the pancreas leads to increased adhesion and extravasation of circulating leukocytes $(5,7,11)$ and to presentation of target antigens by infiltrated macrophages and, perhaps, by endothelial cells themselves (46). Among the primary antigen also some beta cell antigens may become effectively presented by these cells. In individuals who are genetically predisposed for IDDM, presentation of beta cell antigens in islets will then lead to autoimmunity if these antigens are presented in such a manner that they can be recognized by a $T$ lymphocyte infiltrating the islet. After activation of an autoreactive $T$ cell clone, autoaggression against beta cells is initiated, and gradually the process of beta cell destruction is perpetuated by lymphocytes, which are recruited by endothelial cells and which recognize antigens released from damaged beta cells.

In conclusion, we have shown that some macrophages are present in islets during diabetic insulitis and that $T$ cells bearing distinct $T$ cell receptor elements are enriched in islet infiltrates. We have also found increased expression of the adhesion molecule ICAM-1 on the vascular endothelium of the pancreas. We believe that these findings are important for research targeted on the mechanisms of beta cell destruction as well as for the design of interventions intended to arrest the autoimmune process which finally leads to the clinical presentation of IDDM.

\section{Acknowledgments}

We are indebted to Dr. Dorian Haskard for providing monoclonal antibodies against endothelial adhesion molecules, to Dr. Markku Viander for critical review of the manuscript, and to Dr. Tytti Vuorinen for information about virological tests performed.

This work was supported by grants from the Foundation for Pediatric Research, Finland, the Diabetes Research Foundation, Finland, Nordisk Insulinfond, the Farmos Research Foundation, the Finnish Academy, Orion Corp., and Novo Corp., Finland.

\section{References}

1. Gepts, W. 1965. Pathologic anatomy of the pancreas in juvenile diabetes mellitus. Diabetes. 14:619-633.

2. Bottazzo, G. F., B. M. Dean, J. M. McNally, E. H. MacKay, P. G. F. Swift, and D. R. Gamble. 1985. In situ characterization of autoimmune phenomena and expression of HLA molecules in the pancreas in diabetic insulitis. N. Engl. J. Med. 313:353-360.

3. Sibley, R. K., D. E. R. Sutherland, F. Goetz, and A. F. Michael. 1985. Recurrent diabetes in the pancreas iso- and allograft. A light and electron microscopic and immunohistochemical analysis of four cases. Lab. Invest. 53:132-144. 
4. Parrot, D. M. V., and P. C. Wilkinson. 1981. Lymphocyte locomotion and migration. Prog. Allergy. 28:1933-1984.

5. Springer, T. A. 1990. Adhesion receptors of the immune system. Nature (Lond.). 346:425-434.

6. Haskard, D., D. Cavender, P. Beatty, T. A. Springer, and M. Ziff. 1986. T lymphocyte adhesion to endothelial cells: mechanisms demonstrated by antiLFA-1 monoclonal antibodies. J. Immunol. 137:2901-2906.

7. Dustin, M. L., and T. A. Springer. 1988. Lymphocyte function-associated antigen-1 (LFA-1) interaction with intercellular adhesion molecule-1 (ICAM-1) is one of at least three mechanisms for lymphocyte adhesion to cultured endothelial cells. J. Cell Biol. 107:321-331.

8. Dustin, M. L., D. E. Staunton, and T. A. Springer. 1988. Supergene families meet in the immune system. Immunol. Today. 9:213-215.

9. Bevilacqua, M. P., S. Stengelin, M. A. Gimbrone, and B. Seed. 1989. Endothelial leukocyte adhesion molecule-1: an inducible receptor for neutrophils related to complement regulatory proteins and lectins. Science (Wash. DC). 243:1160-1165.

10. Luscinskas, F. W., A. F. Brock, M. A. Arnaout, and M. A. Gimbrone. 1989. Endothelial leukocyte adhesion molecule-1-dependent and leukocyte (CD11/CD18)-dependent mechanisms contribute to polymorphonuclear leukocyte adhesion to cytokine-activated human vascular endothelium. J. Immunol. 142:2257-2263.

11. Munro, J. M., J. S. Pober, and R. S. Cotran. 1989. Tumor necrosis factor and interferon gamma induce distinct patterns of endothelial activation and associated leukocyte accumulation in skin of Papio anubis. Am. J. Pathol. 135:121133.

12. Anderson, D. C., and T. A. Springer. 1987. Leukocyte adhesion deficiency: an inherited defect in the Mac-1, LFA-1 and p150,95 glycoproteins. Annu. Rev. Med. 38:175-194.

13. Smith, C. W., S. D. Marlin, R. Rothlein, C. Toman, and D. C. Anderson. 1989. Cooperative interactions of LFA-1 and Mac-1 with intercellular adhesion molecule-1 in facilitating adherence and transendothelial migration of human neutrophils in vitro. J. Clin. Invest. 83:2008-2017.

14. Lawrence, M. B., C. W. Smith, S. G. Eskin, and L. V. McIntire. 1990 Effect of venous shear stress on CD18 mediated neutrophil adhesion to cultured endothelium. Blood. 75:227-237.

15. Haskins, K., C. Hannum, J. White, N. Roehm, R. Kubo, J. Kappler, and P. Marrack. 1984. The antigen-specific, major histocompatibility restricted receptor on T cells. An antibody to a receptor allotype. J. Exp. Med. 160:452-471.

16. Zamvil, S. S., D. J. Mitchell, N. E. Lee, A. C. Moore, M. K. Waldor, K Sakai, J. B. Rothbard, H. O. McDevitt, L. Steinman, and H. Acha-Orbea. 1988. Predominant expression of a $\mathrm{T}$ cell receptor $\mathrm{V}$ beta gene subfamily in autoimmune encephalomyelitis. J. Exp. Med. 167:1586-1596.

17. Happ, M. P., and E. Heber-Katz. 1988. Differences in the repertoire of the Lewis rat $\mathrm{T}$ cell response to self and nonself myelin basic proteins. $J$. Exp. Med. 167:502-513.

18. Chluba, J., C. Steeg, A. Becker, H. Wekerle, and J. T. Epplen. 1989. T cell receptor beta chain usage in myelin basic protein-specific rat $\mathrm{T}$ lymphocytes. Eur. J. Immunol. 19:279-284.

19. Acha-Orbea, H., D. J. Mitchell, L. Timmermann, D. C. Wraith, G. S Tausch, M. K. Walder, S. S. Zamvil, H: O. McDevitt, and L. Steinman. 1988. Limited heterogeneity of $T$ cell receptors from lymphocytes mediating autoimmune encephalomyelitis allows specific immune intervention. Cell. 54:262-273.

20. O'Reilly, L. A., P. R. Hutchings, P. R. Crocker, E. Simpson, T. Lund, D. Kioussis, F. Takei, J. Baird, and A. Cooke. 1991. Characterization of pancreatic islet cell infiltrates in NOD mice: effect of cell transfer and transgene expression. Eur. J. Immunol. 21:1171-1180.

21. Kontiainen, S., R. Toomath, J. Lowder, and M. Feldmann. 1991. Selective activation of $\mathrm{T}$ cells in newly diagnosed insulin-dependent diabetic patients: evidence for heterogeneity of T cell receptor usage. Clin. Exp. Immunol. 83:347351.

22. Wellicome, S. M., M. H. Thornhill, C. Pitzalis, D. S. Thomas, J. S. S Lanchbury, G. S. Panayi, and D. O. Haskard. 1990. A monoclonal antibody that detects a novel antigen on endothelial cells that is induced by tumor necrosis factor, IL-1 or lipopolysaccharide. J. Immunol. 144:2558-2565.

23. Jalkanen, S., R. F. Bargatze, L. R. Herron, and E. C. Butcher. 1986. A lymphoid cell surface glycoprotein involved in endothelial cell recognition and lymphocyte homing in man. Eur. J. Immunol. 16:1195-1202.

24. Eisenbarth, G. S. 1986. Type 1 diabetes mellitus: a chronic autoimmune disease. N. Engl. J. Med. 314:1360-1368.
25. Foulis, A. K., M. McGill, and M. A. Farquharson. 1991. Insulitis in type 1 (insulin-dependent) diabetes mellitus in man-macrophages, lymphocytes, and interferon $\gamma$ containing cells. J. Pathol. 165:97-103.

26. Foulis, A. K., and M. A. Farquharson. 1986. Aberrant expression of HLADR antigens by insulin containing beta cells in recent onset type 1 diabetes mellitus. Diabetes. 35:1215-1224.

27. Foulis, A. K., M. A. Farquharson, and R. Hardman. 1987. Aberrant expression of class II major histocompatibility complex molecules by B cells and hyperexpression of class 1 major histocompatibility complex molecules by insulin containing islets in type 1 (insulin-dependent) diabetes mellitus. Diabetologia. 30:333-343.

28. Altmann, D. M., N. Hogg, J. Trowsdale, and D. Wilkinson. 1989. Cotransfection of ICAM-1 and HLA DR reconstitutes human antigen presenting cell function in mouse L cells. Nature (Lond.). 338:512-514.

29. Bendtzen, K., T. Mandrup-Poulsen, J. Nerup, J. H. Nielsen, C. A. Dinarello, and M. Svenson. 1986. Cytotoxicity of human pI 7 interleukin-1 for pancreatic islets of Langerhans. Science (Wash. DC). 232:1545-1547.

30. Lee, K. U., C. Y. Pak, K. Amano, and J. W. Yoon. 1988. Prevention of lymphocytic thyroiditis and insulitis in diabetes-prone BB rats by the depletion of macrophages. Diabetologia. 31:400-402.

31. Lee, K. U., K. Amano, and J. W. Yoon. 1988. Evidence for initial involvement of macrophages in development of insulitis in NOD mice. Diabetes. 37:989-991.

32. Hutchings, P., H. Rosen, L. O'Reilly, E. Simpson, S. Gordon, and A. Cooke. 1990. Transfer of diabetes in mice prevented by blockade of adhesionpromoting receptor on macrophages. Nature (Lond.). 348:639-642.

33. Pipeleers, D. G., P. A. In't Veld, M. A. Pipeleers-Marichal, W. Gepts, and M. Van de Winkel. 1987. Presence of pancreatic hormones in islet cells with MHC-class II antigen expression. Diabetes. 36:872-876.

34. Osborn, L. 1990. Leukocyte adhesion to endothelium in inflammation. Cell. 62:3-6.

35. Rice, G. E., J. M. Munro, C. Corless, and M. P. Bevilacqua. 1991. Vascular and nonvascular expression of INCAM-110. A target for mononuclear leukocyte adhesion in normal and inflamed human tissues. Am. J. Pathol. 138:385393.

36. Cross, A., B. Cannella, C. Brosnan, and C. Raine. 1990. Homing to central nervous system vasculature by antigen specific lymphocytes. I. Localization of 14 $C$ labeled cells during acute, chronic and relapsing experimental allergic encephalomyelitis. Lab. Invest. 63:62-70.

37. Schönrich, G., U. Kalinke, F. Momburg, M. Malissen, A. Schmitt-Verhulst, B. Malissen, G. J. Hammerling, and B. Arnold. 1991. Down-regulation of $T$ cell receptors on self reactive $T$ cells as a novel mechanism for extrathymic tolerance induction. Cell. 65:293-304.

38. Ohashi, P. S., S. Oehen, K. Buerki, H. Pircher, C. T. Ohashi, B. Odermett, B. Malissen, R. M. Zinkernagel, and H. Hengartner. 1991. Ablation of "tolerance" and induction of diabetes by virus infection in viral antigen transgenic mice. Cell. 65:305-317.

39. Nakano, N., H. Kikutani, H. Nishimoto, and T. Kishimoto. 1991. T cell receptor $\mathrm{V}$ gene usage of islet $\beta$ cell-reactive $\mathrm{T}$ cells is not restricted in non-obese diabetic mice. J. Exp. Med. 173:1091-1097.

40. Shizuru, J. A., C. Taylor-Edwards, A. Livingstone, and C. G. Fathman 1991. Genetic dissection of $T$ cell receptor $V \beta$ gene requirements for spontaneous murine diabetes. J. Exp. Med. 174:633-638.

41. Zinkernagel, R. M., and P. C. Doherty. 1979. MHC-restricted cytotoxic T cells: studies on the biological role of polymorphic major transplantation antigens determining $\mathrm{T}$ cell restriction-specificity, function and responsiveness. $\mathrm{Adv}$. Immunol. 27:51-177.

42. Parkkonen, P., H. Hyöty, L. Koskinen, and P. Leinikki. 1992. Mumps virus infects beta cells in human fetal islet cell cultures upregulating the expression of HLA class I molecules. Diabetologia. 35:63-69.

43. Yoon, J. W. 1990. The role of viruses and environmental factors in the induction of diabetes. Curr. Top. Microbiol. Immunol. 164:95-123.

44. Pober, J. S., and R. S. Cotran. 1990. The role of endothelial cells in inflammation. Transplantation (Baltimore). 50:537-544.

45. Pober, J. S. 1988. Cytokine-mediated activation of vascular endothelium: physiology and pathology. Am. J. Pathol. 133:426-433.

46. Pober, J. S., M. A. Gimbrone, Jr., R. S. Cotran, C. S. Reiss, S. J. Burakoff, W. Fiers, and K. A. Ault. 1983. Ia expression by vascular endothelium is inducible by activated $\mathrm{T}$ cells and by human gamma interferon. J. Exp. Med. 157:1339-1353 